\title{
DYNAMIC MULTI AGENT SYSTEM FOR REVISING E-LEARNING CONTENT MATERIAL
}

\author{
Fatiha ELGHIBARI \\ ORCID: https://orcid.org/0000-0003-4479-0334 \\ Faculty of Sciences \\ Moulay Ismail University \\ Meknes, Morocco \\ Dr. Rachid ELOUAHBI \\ ORCID: https://orcid.org/0000-0003-3640-8211 \\ Faculty of Sciences \\ Moulay Ismail University \\ Meknes, Morocco \\ Dr. Fatima EL KHOUKHI \\ ORCID: https://orcid.org/0000-0003-1663-4051 \\ Faculty of Arts and Humanities \\ Moulay Ismail University \\ Meknes, Morocco
}

Received Date: 06/01/2018 Accepted Date: 19/04/2018

\begin{abstract}
The growth of the information and communication technologies has led to the appearance of new concepts, approach and disciplines. For learners, an e-learning system constitutes rich window to the knowledge. It presents a varied training, including different content material format (video, text, interactive content...) and diverse methods. In order to keep learners' attention, e-learning system must provide good content's quality, including revised material and updated methods. In this perspective, we have implemented multi-agent system composed of three sort of agents ensuring a permanent revision to the e-learning content. The first one is called Checker Agent (CA). It checks the educational resources, and detects the outdated ones so as to be treated. The second agent is named Search Agent (SA). The task of this one is to look for recent contents and new teaching methods. Whereas, the third agent is called Updater Agent (UA). Its function consists on inserting the retrieved updates corresponding to each content. The communication between these agents is ensured by an XML files. In this paper, we have proposed an implementation of the first part of our system. Namely, the checking process of e-learning curriculum by implementing the $\mathrm{CA}$ algorithm. And the integration process by implementing the UA algorithm. As result, the tests and experimentations done in this context have proved the effectiveness of the proposed solution, and revealed positive results both in term of learning process and learners' feedback.
\end{abstract}

Keywords: e-Learning; updates; revising, XML, multi agents system. 


\section{INTRODUCTION}

E-learning is an intelligent mean to carry out distance education. It facilitates learning by providing different contents formats (video, web page, interactive courses...) regardless of time and place. The success of e-learning systems is due to the variety the proposed services. Namely, it presents content material adapted to the learners' skills, and it customizes their learning path according to their needs and preferences (Viet \& Si, 2006). However, the content material is the most important part in e-learning system, it constitutes a mean of communication between learners and curriculum. And more it is relevant and updated, more it contributes to a good knowledge acquisition. That is why, it must be methodical, organized and continually revised. The objective is to keep track of the evolution of technology and information. Especially, it presents rich opportunities to introduce the latest thinking in given disciplines. Also, to incorporate new methodologies for learning and teaching (Hai-Jew, 2010). In general, learners like using the new advances in term of support format. They are curious to try new tools and learn about new discipline (Arsham , 2014). So, it is necessary to take an interest to the actualization process. However, the process of revising contents can produce some difficulties:

For administrator: the e-learning system is composed of diversity and multitude of contents. The operation of updating can be tiring. Especially in looking for which course need to be revised. Also, it can take a lot of time and effort.

$>$ For learners: sometimes, the operation of updating can stop the teaching service. And, it interrupts learning process. Then, it can disturb learners during learning.

$>$ That is why, it was essential to conceive an intelligent system revising e-learning curriculum by:

$>$ Detecting contents which need revision.

$>$ Perceiving the recent approaches and new contents in the educational environment.

$>$ Integrating new updates into the curriculum gradually without interrupting learning process.

To achieve that, we conceived a multi-agent system composed of three agents: the first one called Checker Agent (CA), responsible for detecting outdated contents. The second one named Search Agent (SA). It looks for the latest updates and retrieves new disciplines. And finally, Updater agent (UA), its role consists on seeking for updates (recorded contents) locally, and integrates them into the curriculum. The objective of this article is to revise e-learning contents and also, reduce time and labour devoted for this operation. In term of our system, the CA and UA act in an automated and dynamic way. They work permanently in order to detect obsolete contents without any human intervention. And during learning process the updates' integration happens ordinary without stopping learning system or disturbing learners.

The paper is structured as follows. Section 2 includes a brief overview of related work in the field of adoption intelligent agent technology in e-learning systems. Section 3 describes the features of the proposed updating process. Section 4 presents the implementation of the proposed solution managing the updates and discusses the experimentation's result. Finally, Section 5 summarizes the prospects and future extensions of the proposed elearning system.

\section{RELATED WORK}

The extensive use of e-learning system has led to the emergence of lot of studies in order to enhance the quality of the proposed services. Some researchers opted to the use of intelligent agents seen their autonomy and their capacity to make decision according to the changing environment (Gregg, 2007). In the field of adaptation, several Multi agents system have been conceived so as to reduce the incompatibilities between the difficulties' 
degree of teaching materials and learners' skills. For example, ( Méndez, Marín, \& Carranza, 2018) proposed an intelligent system for learners' personal assistance. The objective is to support learner for selecting educational material from learning objects repositories. Based on the intelligent agents, it can access to his profile and retrieves information about his preferences and his skills. It is a recommendation system based on the similarity between learners' characteristics, and the former learning experiences. The tests' results were satisfactory, it allows to improve the relevance of the materials for each particular student. Also, the research work of (Yilmaz, Olpak, \& Yilmaz, 2017) revealed an intelligent model for self-regulatory skills in order to ensure success in the Flipped Classroom (FC). The model is based on pedagogical agent that provides metacognitive support (MS) during the online learning. The results have a statistically significant higher. They proved that pedagogical agent contributes to the development of self-regulation skills of learners. The research work of (Dolen \& Aberšek, 2015) revealed an individualized intelligent tutoring system called TECH8. The model propose personalized curriculum based on the cognitive characteristics of the individual learner. It can be adapted to each individual's level of knowledge. The experimentation results demonstrated that appropriately created TECH8 e-learning material, yields positive results better than those from traditional teaching, but not better than one to one teaching. Likewise, (Sweta \& Lal, 2017) conceived learning model for customizing learners' path. The system extracts learner's navigational accesses data and finds learner's behavioral patterns which individualize each learner and provide personalization according to their learning styles. The results showed that personalized adaptive elearning has promising results that help learners to proceed.

The objective of the majority of researches in the field of e-learning, is to ensure learners' progression, and their evolution. For instance, (Anghour \& Lamolle, 2017) presented a new architecture of learning path generation and managing the learner's progression in multi-users context. The objective is to improve learners' progression in the collaborative learning path. The graph of learning objects is build according to their prerequisites and according to their progression. The results of tests evaluation of the proposed multi-agent system have a positive impact on learners' performance. Also, (Song, Oh , \& Rice, 2017) developed a conversational agent system to promote the learner's meaningful interaction in online courses. The system demonstrate that the quality interactions between the learner and the conversational agent is applicable to graduate-level online courses and improve learners' performance.

Several researches works have been carried out in the field of optimization. For example, (Bourbia, Seridi , Hadjeris , \& Seridi, 2012) conceived an adaptive e-learning platform using the Ant colony optimization (ACO), it has been modelled as graphs whose nodes represent the pedagogical elements (classes or exercises), and arcs represent navigation links between them. Each arc has a value describing its importance to teaching neighboring arcs. Students are represented by virtual agents (ants) using these links. The studies of (Elouahbi, Bouzidi, Abghour, \& Nassir, 2012) proposed an approach based on the SmartGraph in order to optimize the educational path according to each learners' needs. The proposed model is a graph where nodes represent learning units and the arcs represent the educational constraints between units. ACO Algorithm can be used also as an intelligent agents in order to provide a flexible educational content suited to changing learner's skills and their evolution during the training (Elghibari, Elouahbi, \& El Khoukhi, 2015). It can be used to optimize collaborative learning path by creating groups called homogeneous teams, based on a set of criteria to highlight the similarity between the learners. The optimal path of each community is built, through a dynamic adaptation of the optimization technique by ACO (Kamsa, Elouahbi, El khoukhi, Karite, \& Zouiten, 2016).

Intelligent agents are used also in the field of reconstruction of e-learning courses, including updates and revising (Elghibari, Elouahbi, Elkhoukhi, Chehbi, \& Kamsa, 2015). The research work of (Arif, et al., 2014) proposed 
Multi agent system for updating content through question and answer between e-learners and intelligent agents as to extract their feedback, their expectations, and their satisfaction level (Elghibari, Elouahbi, El Khoukhi, Ezzahri, \& Amali, 2016). Whereas, the study of (Zhang, Zhou, Briggs, \& Jr, 2006) proved the important of the integration of interactive instructional video. The finding revealed that it achieves better learning performance and high level of learners' satisfaction (Kamsa, Elouahbi, \& El khoukhi, 2017). However, (Agarwal \& Ahmed, 2017) developed system called Collective learning extension. The main objective is to keep the curriculum up to date. The system is adaptable to existing learning paradigms. It creates a curriculum development strategy adaptive to the rapidly evolving technologies. The system proved its efficiency in term of encouragement and collaboration. Also, (Tarasowa, Khalili, \& Auer, 2015) Proposed the CrowdLearn approach which consist on combining the wiki style for collaborative content authoring with SCORM requirements for re-usability. It splits the learning material into Learning Objects (LOs) with an adjustable level of granularity. The evaluation results revealed that the proposed approach is a good manner for revising and creating e-learning content. In term technology' innovation in e-learning, ( $\mathrm{Ng}$, Lam, $\mathrm{Ng}$, \& Lai, 2017) identified suitable pedagogical practices and methods for more effective learning and teaching in the Vocational and Professional Educational and Training's workplaces. The findings revealed that technology's advances permits to improve learning process, and enhance interaction and motivation. The research of (Bhaskaran \& Swaminathan, 2014) revealed a robust multi agents system that customizes learning path and ensures the pursuit of teaching in the case of intermittent connections. The studies of (Lin, Holt, Leung, \& Li, 2006) identified an Adaptive e-learning systems using a mixed of intelligent agents and web services technology in order to integrate different distributed knowledge and data resource, this architecture allows to share information between applications for reuse and interoperability. Namely, providing tutorial, exercises and assessment suited to the performance and the preferences of each learner (Giuffra, Cecilia , \& Silveira , 2013).

Some researches has oriented to XML technology. For example, (Cojocariiu \& Stanciiu, 2009) developed an application that facilitates the assistance of learners and the development of validation tests in e-learning system. However, (Kautsar, Kubota, Musashi, \& Sugitani, 2013) realized an approach to standardize the format of the tests between different LMS. The objective was to ensure the portability of files, namely facilitating the exchange of content between Moodle and Chamilo for example. Others research works have focused on tracking learner's behaviour in order to identify its blocking and resolve them (Chehbi, Elouahbi, \& El khoukhi, 2016).

Intelligent agents have proved their efficiency to resolve the most complex problem, it has been used to solve adaptation' problem, customizing learning time (Kamsa, Elghibari, Elouahbi, Chehbi, \& El Khoukhi, 2015), updating, content's quality...the majority of researches work proposed adaptive systems and recommendation systems. The objective is to present relevant content to learner adapted to his skills and cognitive capacities. Namely, intelligent adaptive systems focus primarily on reducing the gap between learners' skills and the difficulty of teaching resources. In some cases, this type of system becomes unable to detect if the educational content is updated or not. Does it suit information and technology evolution? Are new disciplines considered for integration into the system or not? On the other hand, it seems easier to update e-learning contents than traditionally published documents, however there are some practical difficulties (cost, time of trainers) to maintain e-learning. The e-learning content can be difficult to revise and maintain due to lack of ownership and responsibility for the e-learning content. Online content developers may not be the ones who update it (Carliner $\&$ Shank, 2008). Also, it can be emphasized that it requires a lot of modelling work and therefore too much maintenance costs to consider its application to an open or evolving domain. That is why, our research work aims to conceive an intelligent system that permits to detect obsolete contents, and search updates in order to 
keep to date the e-learning system. The revision' integration must be gradually in the curriculum without interrupting learning process, or spoil learners' concentration.

\section{MODEL OF MULTI AGENT SYSTEM FOR REVISING E-LEARNING COURSES MATERIAL}

The main goal of our research is providing relevant e-learning curriculum. The system must be able to perceive the new approaches, and recent disciplines in the educational environment. Especially, it must facilitate their integration gradually without disturbing learners during learning. Also, reduce time and labor devoted for this operation. To achieve that, we need a mechanism that can perceive the changing environment. And, react according to these changes. That is why, we opted to the use of intelligent agents (Russell \& Norvig, 2009), seen their autonomy and their ability to solve the most complex problems. We have proceeded by proposing a multiagent system, composed of three sort of agents. The first one called Checker Agent (CA). It checks the content's validity in database. The second named Search Agent (SA). Its role is to looks for latest updates of contents in the internet repositories. And finally, the third one named Updater Agent (UA). Its role consists on inserting updates in learning curriculum. These agents communicate through XML files as shown in the following figure (Fig.1).

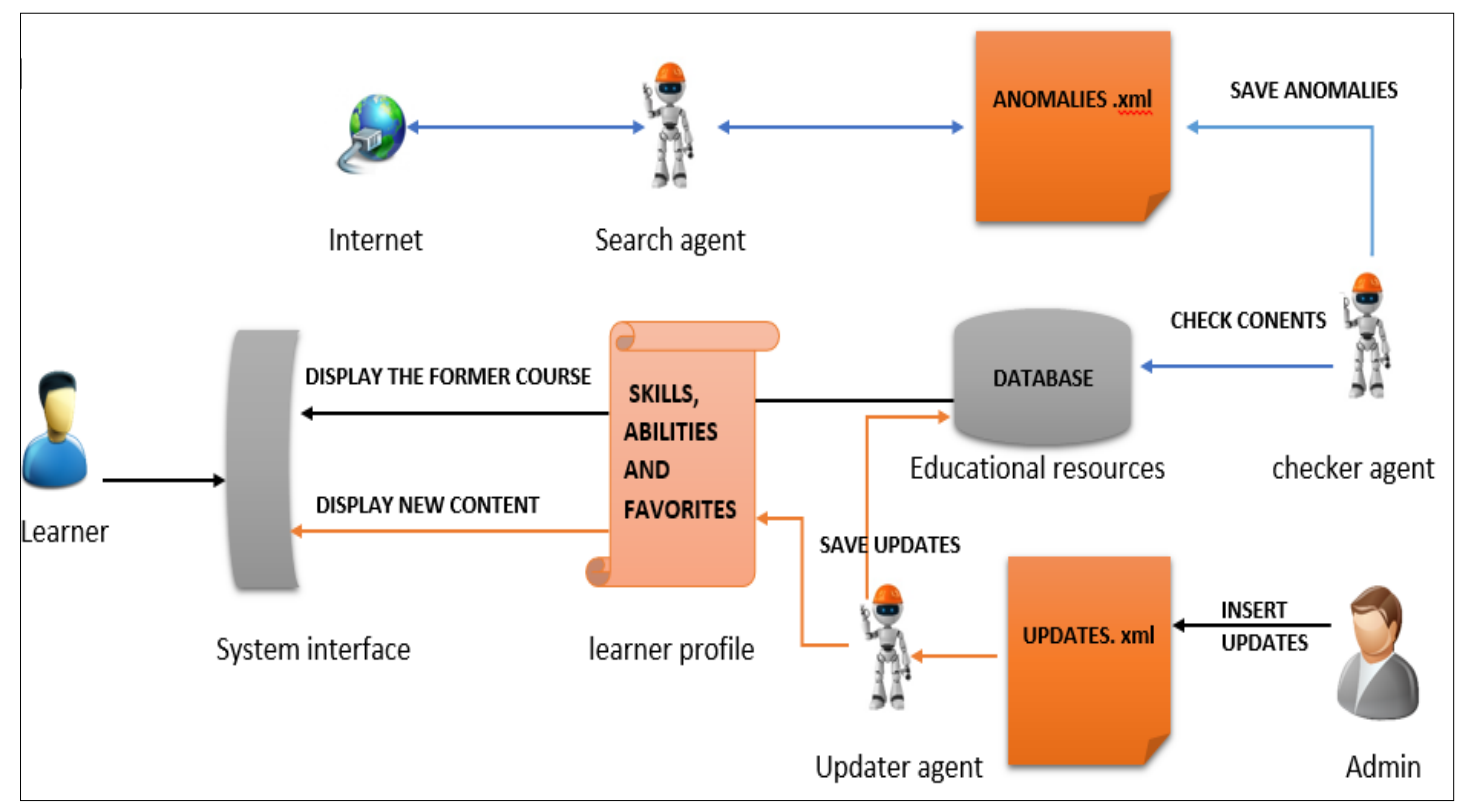

Figure 1. Model of multi agent system for updating contents.

\section{Checker Agent's Algorithm}

In order to ensure relevant and creative contents. E-learning curriculum must be revised all the time (Elghibari, Elouahbi, \& El Khoukhi, 2017). However, new methodologies and tools take at least 1 year for their expansion. One year is enough to measure the performance and the added values of new advances and updates. Namely, insert it if it has succeeded, or avoid it in the opposite case. That is why, we define an annual period for each content to be revised. The role of CA is checking the validity of the educational resources. It browses database and detects the former contents. Namely, that have been published previously as explained in the following algorithm (Algo.1). 


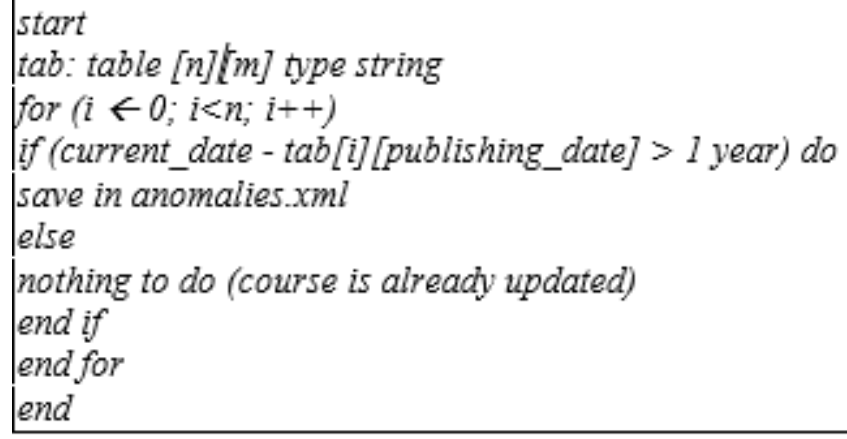

Algo.1 Checker agent's algorithm explaining the process of checking e-learning contents

First, it compares the publishing date of each educational material with the current date. In other word, it calculates the gap between the date of last edition of content's and the current date. If the difference exceeds one year, the CA considers it as an anomaly. And, saves it in anomalies.xml file. If not, that means that the course does not need any revision.

\section{Search Agent}

The role of search agent consists on seeking the latest updates of courses marked as anomalies. Search operation is based on the criteria recorded in anomalies.xml file. Connected to the internet (digital libraries databases, server repositories), it retrieves the search's results by saving their links in the same file. The results of this research may reveal a variety of contents materials in different formats. So, to provide a good of e-learning content, the authors' committee asses and judges the quality of content's information recorded by the SA. This committee is composed of a set of professors and specialists. Their principal role consists on checking, editing different format (slides, video, web page...) and creating another ones.

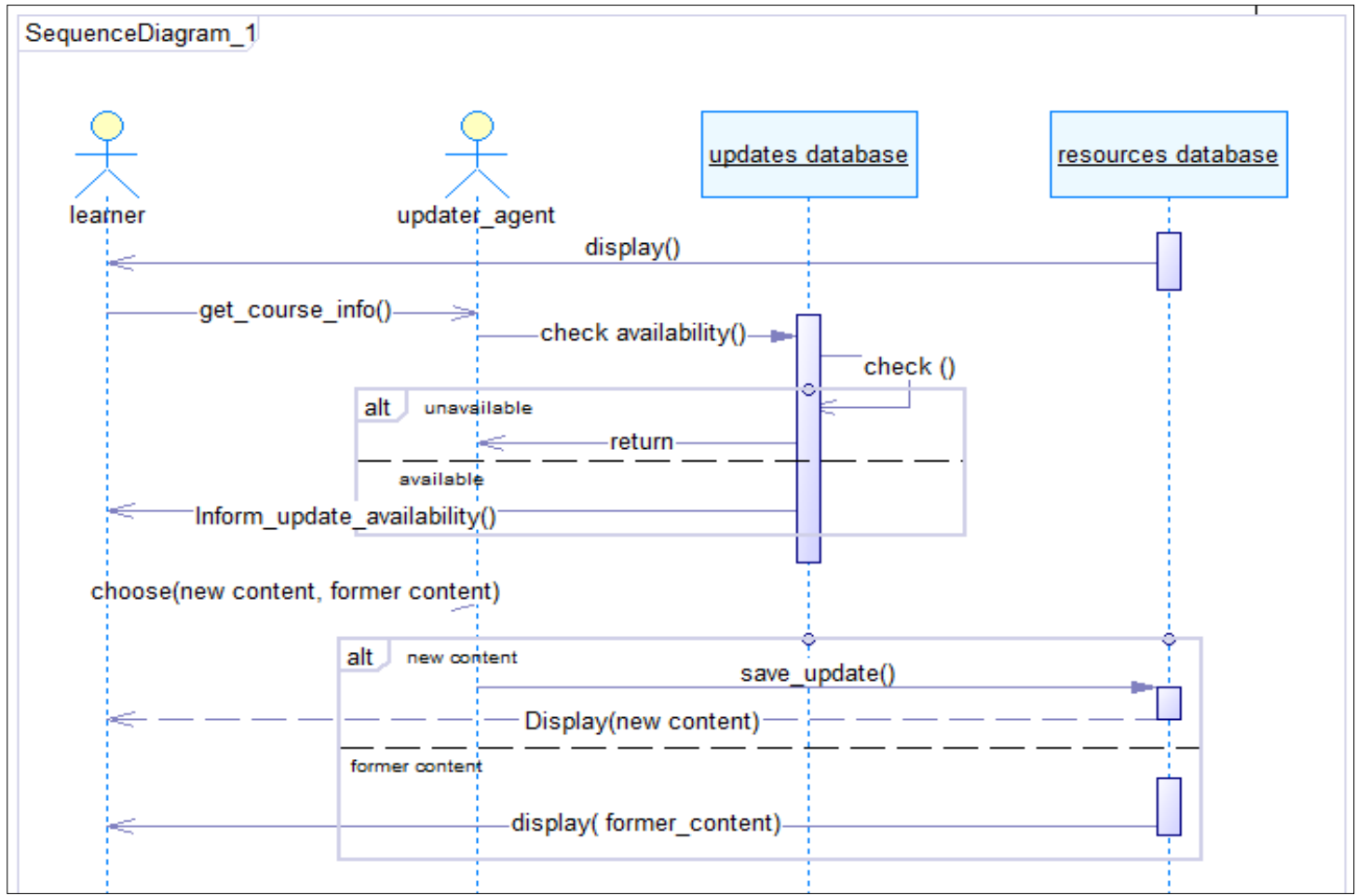

Figure 2. Sequence diagram explaining the algorithm of the integration of new content material. 


\section{Updater Agent's Algorithm}

The objective of this paper is to test the local updating process. That is why, we consider that we have already retrieved new updates. Once the new revised courses are ready. The administrator inserts them in updates.xml file. The UA proposes to learners to learn in the new version. The role of this agent is to insert updates into the curriculum gradually as not to disturb learning process of learners, and spoil their concentration. The process of integration is explained in the following figure (Fig.2).

Once connected, learner consults his course in order to continue his training. The UA gets information about the read material. And it checks if there is new corresponding update or not. If it is available, the UA displays a message to learner inviting him to read the new version. If not, agent doesn't involve, and learner continues his learning. In the case of an existing updates, the UA intervenes according to the choice of learner.

$>$ If learner prefers the revised course: The UA integrates it automatically in the curriculum. Then, it will be displayed so as to pursue his learning.

If he chooses the former one: The UA registers it in database. So, these updates will not be shown to him. It will be integrated completely in curriculum after completing learning in the former one.

\section{Structure of updates.xml File}

In order to facilitate new courses' integration, we need to store their information in xml file. It constitutes a Meta data file containing description updates in structured manner. XML is a description language for describing and structuring a set of data according to a set of rules and constraints defined. It can be considered as a database. Namely, it is self-descriptive because the tags describe the structure and the type names of data. Also, it is portable, encoded in Unicode, as it describes data in the tree or graph form. We have chosen XML technology to store updates seen its accessibility and structure.

$>$ Structure: it organizes information to be readable and understandable.

$>$ Accessible: in order to be accessed by the UA in order to incorporate its content into the educational resource's database.

To achieve that, we need to consider the course quality. That is why the updates.xml file must describe the relevant parameters characterizing educational content, as shown in the following figure (Fig. 3).

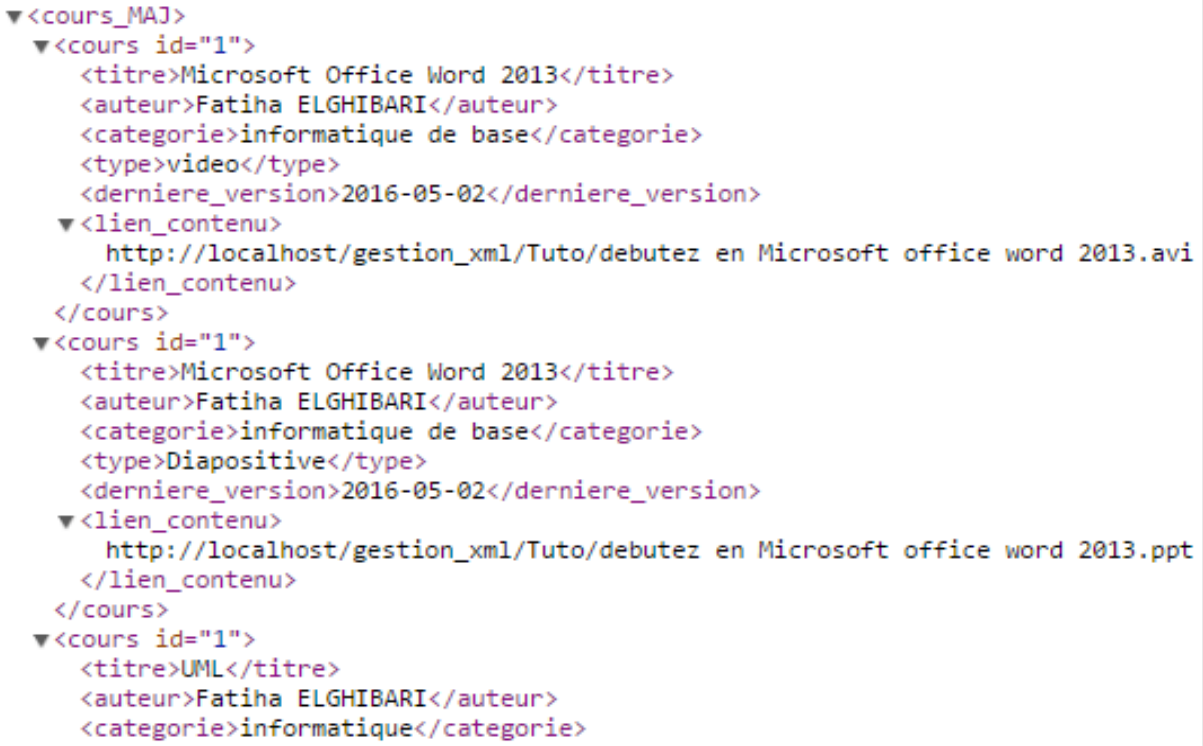

Figure 3. updates.xml file. 
The Training (course) is composed of several materials, each content material is characterized by a set of elements. Administrator must introduce these components in the XML file. Namely:

$>$ Name: learning object name.

$>$ Author: the name of author who edited the course.

$>$ Last_update: last update date or publishing content date.

$>$ Format: contains a set of materials content types (video, text (PDF), web page (HTML), presentation (ppt) ...).

$>$ Category: the category of content material.

$>$ Link: the path of updates.

\section{IMPLEMENTATION OF UPDATING PROCESS MODEL}

\section{The Implementation of the Local Updating Process}

The proposed system is based on set of agents that communicate through xml files in order to integrate new contents automatically in the e-learning curriculum. We have realized the CA and UA algorithm. The integration of new contents happens through updates.xml file. That is why, it was necessary to conceive software application allowing the prepared content's insertion. The software solution permits to define their metadata in order to facilitate their handling later (editing, removing, and updating). To achieve that, we have used the class DOM (Document Object Model) allowing loading contents and saving them in updates.xml database. We have chosen PHP5 as programming language, and Codeigniter framework to organize data manipulation according to MVC model (Fig.4).

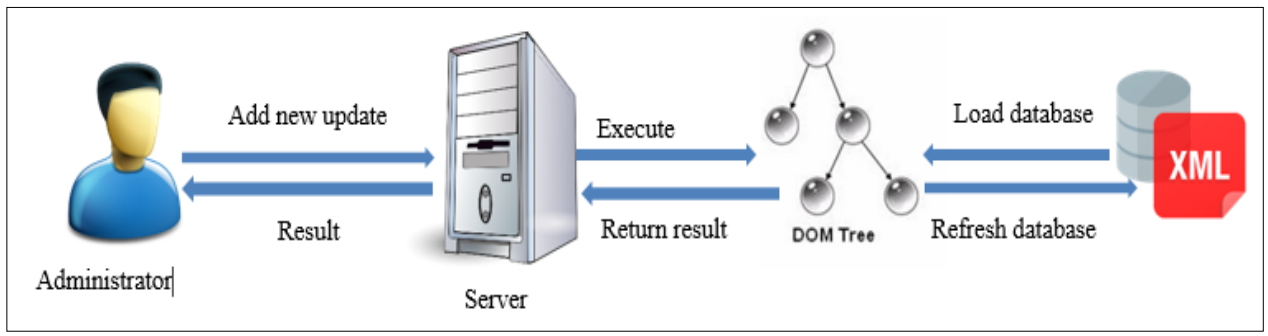

Figure 4. The architecture software application of updating process

\section{Evaluation and results}

Once the administrator logs in, the system displays the list of updates. He can search, edit, and add new update as shown in the following interface (Fig. 5)

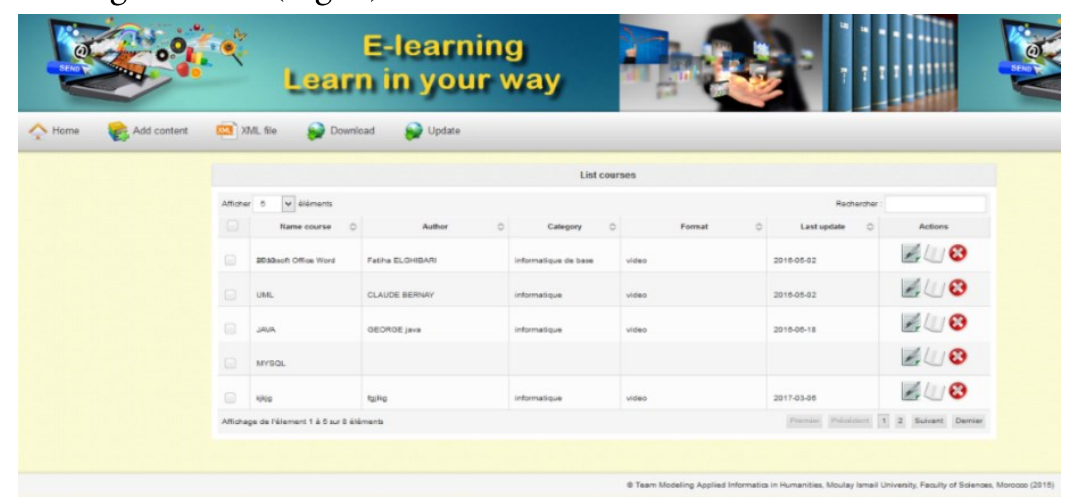

Figure 5 list of contents in updates.xml file

In the other side, the system signals the availability of new updates. And displays a new message to learner inviting him to discover the new content as shown in (Fig.6). 
We have tested our system in Faculty of Humanities, Meknes, Morocco (http://www.flsh.umi.ac.ma/). Namely, evaluate its performance in term of ensuring local updating process. 100 learners from "History and civilization" department have been involved in this experimentation. The majority of them have some comprehending problems and technical difficulties with computing subjects. Learning this sort of subject according to the traditional manner make them dissatisfied. Sometimes they found it difficult to understand. To avoid this type of problems, we have proposed a new course "Microsoft office word 2013" instead "Microsoft office 2010" in term of content. And in term of technology, the new content use new teaching method. It includes new short video explaining each items, interactive contents, examples allowing them to understand the main objective of each functionality. And also, short test unit so as to motivate them and keep their concentration. Inserting updates has revealed a positive impact to learner's performance. Namely, a positives results in term of scores as shown in the following histogram (Fig.7).

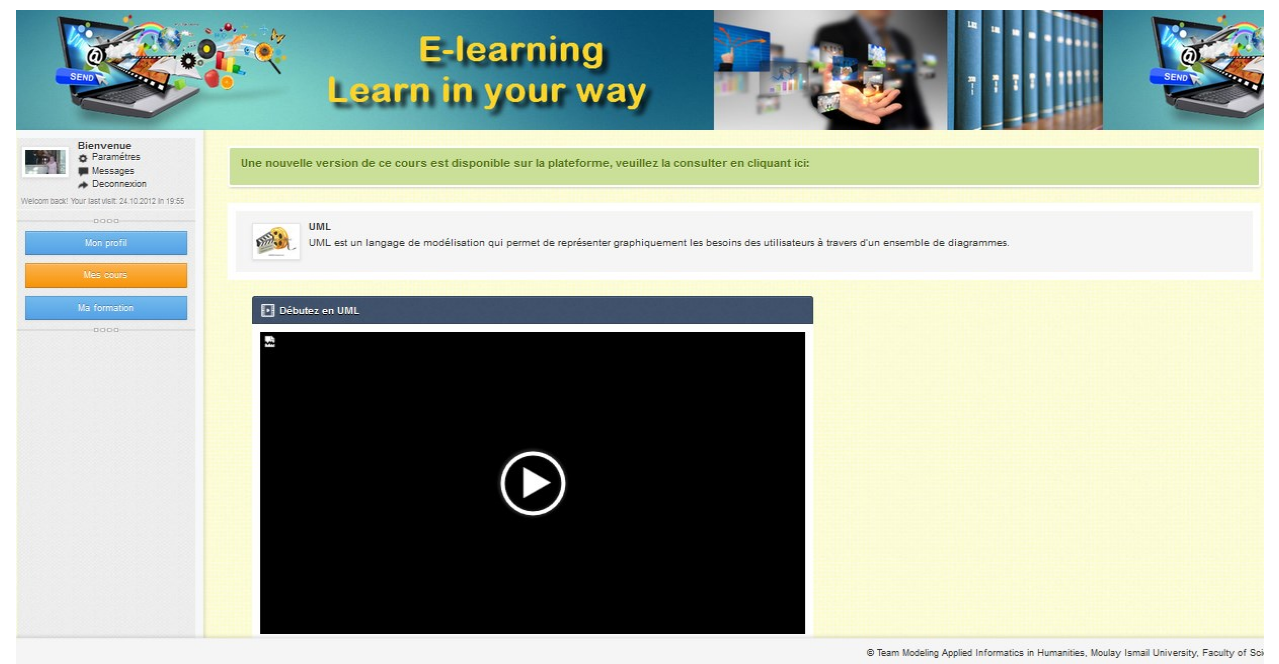

Figure 6. The UA informs learner the availability of new version of content stored in updates.xml file

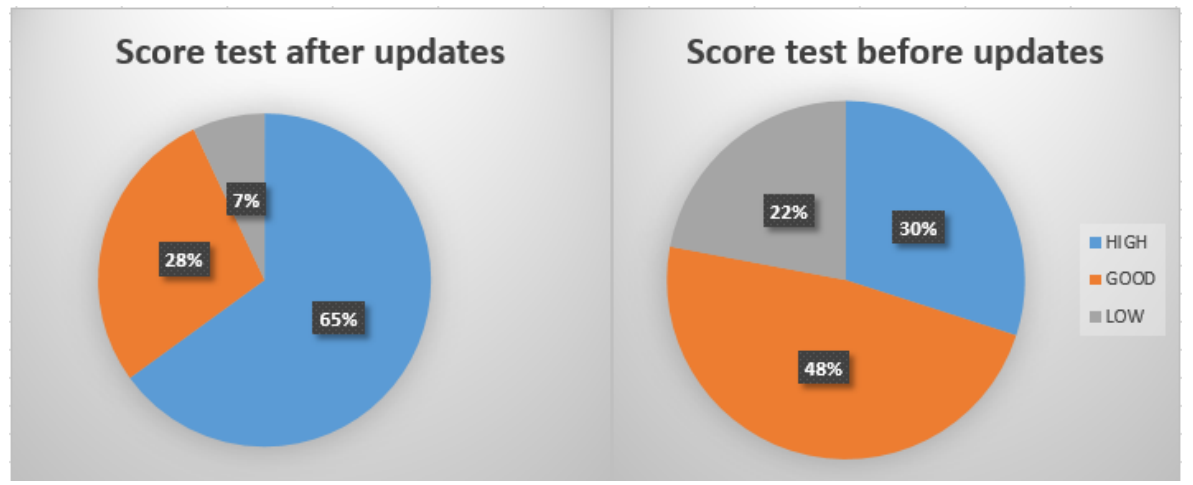

Figure 7. The difference between scores' test before and after integrating updates

Once inserted in the system, (85\%) of learners have chosen new course material (Microsoft office word 2013). It is an important rate proving that learners are very interested to learn new methodologies. It reveals also, that they are excited to know the recent functionalities and also discover the add values in given disciplines. 
We have collected their scores in test assessment after completing their training. (65\%) of them obtained high scores, $(28 \%)$ obtained good scores and only $7 \%$ had low scores. This results have revealed that about two thirds of the involving learners have obtained a high scores. It is an interesting number which reflects clearly the relevance of the presentation and the diversity of the proposed course. It provides different format according to the preferences of students. However, the remaining one third is represented by 28 learners that obtained good marks. And, only 7 students obtained low marks, which can be due to the language problem. Especially, their official learning language is Arabic and language of software tools (Microsoft office word) are learned in French or English. So, they don't understand some key words used in it. And also, it can be due to some difficulties in manipulating software tools seen their lack of interaction with computer.

We have retrieved also their feedback. It was positive in general, $(87 \%)$ of learners were satisfied with the proposed content. However (13\%) were dissatisfied which can be due to their lack of interaction with computer and some difficulties in handling computing tools. The experimentation result's reveals clearly the importance of our system. For example, in term of detecting content's anomalies, it works correctly and automatically. Also, in term of updating process, revised versions are integrated automatically without stopping learning process or disturbing learners. That is why, we realized a high level of learners' satisfaction. The system proves also, that anomalies affecting learners during training not always due to adaptation or customization problems. But, it can due also to the absence of updates, or lack of content's reconstruction. It reveals that outdated contents can be a strong anomaly preventing learning success. We conclude that our software solution has a positive influence on learners' performance. And consequently, an excellent impact on their satisfaction and their motivation.

\section{CONCLUSION AND FUTURE RESEARCH DIRECTIONS}

In this paper, we proposed an automatic multi agents system for updating courses. We realized the first part of the system, by developing an application which searches the retrieved updates locally. And introduce them in the curriculum. We developed the CA algorithm responsible for checking learning content and UA algorithm that completes the updating process's performance. As it is shown in the experimentation results, integrating updates has a positive impact on learners' acquisition and level success.

We are working on SA (Search Agent) that seeks for relevant updates in the whole library which is internet. This part is responsible for searching updates in the server (not locally). That is why, we must use a set of algorithm and techniques allowing to retrieve the most important advances and the relevant information. The search must be accurate and focused. Namely, due to the information overload in the internet, the Search Agent's algorithm must be well implemented by using semantic web, ontology...So, it can be very long to explain it here. That is why, our next work will be devoted for implementing and testing this algorithm in order to accomplish the whole updating process and make it more efficient.

The revising process doesn't depend only on the publishing date. But, it relies also to learners' feedback. Indeed, the new proposed contents can meet their needs or not. So, it is necessary to identify their level of satisfaction after introducing the revised course in order to meet their preferences and their convenience. Our next study will be devoted for measuring level of learners' satisfaction after updating process. 


\title{
BIODATA and CONTACT ADDRESSES of AUTHORS
}

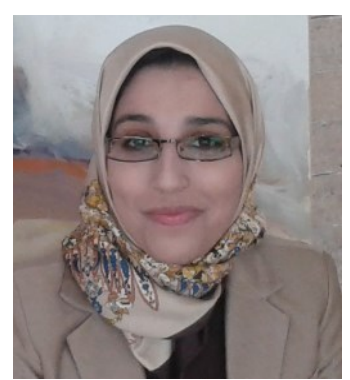

Fatiha ELGHIBARI is a PhD student in Mathematics and Computer Sciences department at Moulay Ismail University, Meknes, Morocco. She is a computer sciences engineer, graduated at June, 2012 from the National School of Applied Sciences, Fez, Morocco. She is a temporary professor in the Faculty of Arts and Humanities, besides the Moroccan Higher School of Computer Science and Management (EMSIG), Meknes Morocco. She is member of Computer Sciences and Applications Laboratory in the Faculty of Sciences of Meknes. Her research works are focusing on e-learning contents anomalies, the maintenance of educational resources and adaptation problems. She has numerous articles and international communications in these fields.

\section{Fatiha ELGHIBARI}

Department of Mathematics and Computer Science, Faculty of Sciences Moulay Ismail University, 50000, Meknes, Morocco

Phone: +212617412261 ,

E-mail: elghibari.fatiha@gmail.com

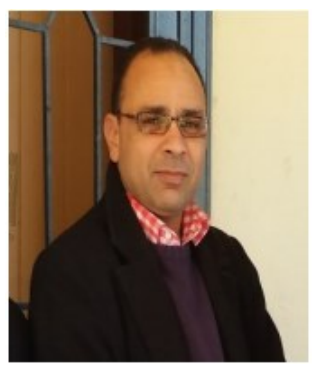

Rachid ELOUAHBI is a Professor of Computer Sciences at Moulay Ismail University, Meknes, Morocco. He gained his Ph.D in Educational Technology at June, 2005 from the Mohammadia School of Engineering. His academic interest areas are adaptive learning systems, machine learning, course sequencing and learning technologies. He has over than 15 journal articles published in international indexes. He is a director of many doctoral theses and he has founded the team of Modeling Applied Informatics in Humanities. He is also a member of Computer Science and Applications Laboratory in Faculty of Sciences at Moulay Ismail University.

\section{Dr. Rachid ELOUAHBI}

Department of Mathematics and Computer Science, Faculty of Sciences

Moulay Ismail University, 50000, Meknes, Morocco

Phone: +21263349577

E-mail: elouahbi@yahoo.fr

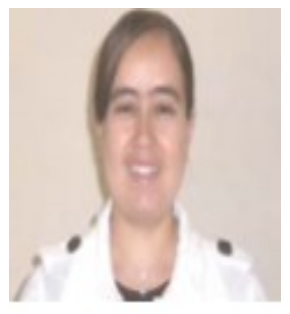

Fatima EL KHOUKHI is a Professor of Computer Sciences at Moulay Ismail University, Meknes, Morocco. Her academic interest areas are operational research, scheduling and metaheuristics problems. She has numerous works in these areas. She is also a director of many doctoral researches. Dr. Fatima EL KHOUKHI is a member of the Modelling Applied Informatics in Humanities team in Faculty of Humanities of Meknes, Morocco and a member of Operational Research and Computer team in Faculty of Sciences and Techniques of Fez, Morocco.

\author{
Dr. Fatima EL KHOUKHI \\ Faculty of Arts and Humanities \\ Moulay Ismail University, 50000, Meknes, Morocco \\ Phone: +21258742276 \\ E-mail: el_khoukhi_fatima@yahoo.fr
}




\section{REFERENCES}

Anghour , A., \& Lamolle, M. (2017). Designing and Managing a Real-Time Collaborative Learning Paths by a Multi-agents Platform. Springer: Recent Advances in Information Systems and Technologies. WorldCIST 2017. Advances in Intelligent Systems and Computing, 571.

Méndez, N. D., Marín, P. A., \& Carranza, D. A. (2018). Intelligent Personal Assistant for Educational Material Recommendation Based on CBR. Springer:Personal Assistants: Emerging Computational Technologies. Intelligent Systems Reference Library, 132, 113-131.

Song , D., Oh , E. Y., \& Rice, M. (2017). Interacting with a conversational agent system for educational purposes in online courses. 10th International Conference on Human System Interactions (HSI). Ulsan, South Korea : the IEEE Digital Library Explorer .

Yılmaz, F. G., Olpak, Y. Z., \& Yilmaz, R. (2017). The Effect of the Metacognitive Support via Pedagogical Agent on Selt-Regulation Skills. Journal of Educational Computing Research, 56(2), 159-180.

Agarwal, N., \& Ahmed, F. (2017, January). Developing collective learning extension for rapidly evolving information system courses. Springer:Education and Information Technologies, 22(1), 7-37.

Arif, M., Illahi, M., Karim, A., Shamshirband, S., Alam, K. A., Farid, S., . . Balas, V. E. (2014). An architecture of agent-based multi-layer interactive e-learning and e-testing platform. Springer Science+Business Media , 1-24.

Arsham , H. (2014, March). Interactive Education: Impact of the Internet on Learning \& Teaching. Retrieved Febraury 2018, from http://home.ubalt.edu: http://home.ubalt.edu/ntsbarsh/interactive.htm

Bhaskaran , S., \& Swaminathan, P. (2014). Intelligent Adaptive E-learning Model for Learning Management System. Research Journal of Applied Sciences, Engineering and Technology, 16(7), 3298-3303.

Bourbia, R., Seridi , A., Hadjeris , M., \& Seridi, H. (2012). An Adaptive Learning Based on Ant Colony and Collaborative Filtering. Proceedings of the World Congress on Engineering, 2, 1-3.

Carliner, S., \& Shank, P. (2008). The e-Learning Handbook: Past Promises, Present Challenges. San Francisco: Wiley.

Chehbi, S., Elouahbi, R., \& El khoukhi, F. (2016). Tracking of learners' motivation and involvement in moodle. The International Journal of Multi-disciplinary Sciences, 2(2), 22-28.

Cojocariiu, A., \& Stanciiu, C. O. (2009). XML Technologies in Computer Assisted Learning and Testing Systems. Annals. Computer Science Series, 7(1), 89-94.

Daomin, X. (2013). Multi-Agent Based e-Learning Intelligent Tutoring System for Supporting Adaptive Learning. Fourth International Conference on Intelligent Systems Design and Engineering Applications (pp. 393-397). IEEE Xplore Digital Library.

Dharshini, A. P., Chandrakumarmangalam, S., \& Arthi, G. (2015). Journal Applied Mathematics and Computation, 263 (C), 332-341 .

Dolen, K., \& Aberšek, B. (2015). TECH8 intelligent and adaptive e-learning system: Integration into Technology and Science classrooms in lower secondary schools. Elsevier:Computers \& Education, $82,354-365$. 
Elghibari, F., Elouahbi, R., \& El Khoukhi, F. (2015). modèle d'un processus d'apprentissage adapté aux évolutions cognitives du profil de l'apprenant. lère Edition du Workshop International sur les Approches Pédagogiques \& E-Learning, (pp. 1-3). Fez, Morocco.

Elghibari, F., Elouahbi, R., \& El Khoukhi, F. (2017). An Automatic Updating Process to Control The Elearning Courseware. International Journal on Advanced Science, Engineering and Information Technology, 7(2), 546-551.

Elghibari, F., Elouahbi, R., El Khoukhi, F., Ezzahri, L., \& Amali, S. (2016). the 15th International Conference onIntelligent model for measuring learners' satisfaction towards new contents. Information Technology Based Higher Education and Training (ITHET) (pp. 1-5). Istanbul, Turkey: IEEE Xplore Digital Library.

Elghibari, F., Elouahbi, R., Elkhoukhi, F., Chehbi, S., \& Kamsa, I. (2015). Intelligent e-learning system model for maintenance of updates courses. 15th International Conference on Information Technology Based Higher Education and Training. Lisbon, Portugal: IEEE.

Elouahbi, R. (2005). Mdélisation et mise en œuvre du séquencemet dans le système de télé-enseignement SMART-Learning via le graphe pédagogique SMART GRAPH .

Elouahbi, R., Bouzidi, D., Abghour, N., \& Nassir, A. M. (2012). A flexible approach to modelling adaptive course sequencing based on graphs implemented using XLink. International Journal of Advanced Computer Science and Applications (IJACSA), 3(1), 1-9.

Giuffra , P., Cecilia , E., \& Silveira , A. R. (2013). A multi-agent system model to integrate virtual learning enviromnents and intelligent tutoring system. International Journal of Artificial Intelligence and Interactive Multimedia, 2(1), 51-58.

Gregg, D. G. (2007). E-learning agents. The Learning Organization, 14(4), 300-312.

Hai-Jew, S. (2010, December 15). An Instructional Design Approach to Updating an Online Course Curriculum. Retrieved Fevrier 12, 2018, from https://er.educause.edu:

https://er.educause.edu/articles/2010/12/an-instructional-design-approach-to-updating-an-onlinecourse-curriculum

Kamsa, I., Elghibari, F., Elouahbi, R., Chehbi, S., \& El Khoukhi, F. (2015). Learning time planning in a distance learning system using intelligent agents. 14th Information Technology Based Higher Education and Training (ITHET). Lisbon, Portugal: IEEE.

Kamsa, I., Elouahbi, R., \& El khoukhi, F. (2017). Intelligent Agents for Dynamic Optimization of Learner Performances in an Online System. Journal of Information Technology Education: Research (JITE:Research), 16, 31-45.

Kamsa, I., Elouahbi, R., El khoukhi, F., Karite, T., \& Zouiten, H. (2016). Optimizing collaborative learning path by ant's optimization technique in e-learning system. The 15th International Conference on Information Technology Based Higher Education and Training (ITHET). Istanbul, Turkey: IEEE Explore Digital Library.

Kautsar, I. A., Kubota, S.-I., Musashi, Y., \& Sugitani, K. (2013). Moodle xml to IMS QTI assessment test portability on learning management system. The Proceedings of The 7th ICTS, (pp. 209-214). Bali.

Lin, F., Holt, P., Leung, S., \& Li, Q. (2006). A multiagent and service-oriented. Int. J. Cont. Engineering Education and Lifelong Learning, 16, 77-91. 
Ng, R. Y.-K., Lam, R. Y.-S., Ng, K. K., \& Lai, I. K. (2017). Identifying the Needs of Flexible and Technology Enhanced Learning in Vocational and Professional Education and Training's (VPET) Workplaces. Springer:New Ecology for Education — Communication X Learning, 107-117.

Russell , S., \& Norvig, P. (2009). Artificial Intelligence: A Modern Approach. Library of Congress Catalogingin-Publication Data.

Sweta , S., \& Lal, K. (2017). Personalized Adaptive Learner Model in E-Learning System Using FCM and Fuzzy Inference System. Springer: International Journal of Fuzzy Systems, 19(4), 1249-1260.

Tarasowa, D., Khalili, A., \& Auer, S. (2015). CrowdLearn: Crowd-sourcing the Creation of Highlystructured E-Learning Content. International Journal of engineering pedagogy, 5(4), 47-54.

Zhang, D., Zhou, L., Briggs, R. O., \& Jr, J. F. ( 2006). Instructional video in e-learning: Assessing the impact of interactive video on learning effectiveness. Elsevier, 43(1), 15-27. 